\title{
Epidemiology of paediatric poisoning reporting to a tertiary hospital in Ghana
}

\author{
D Ansong, ${ }^{1,2,4}$ MD, MSc; C Nkyi ${ }^{3}$ MD; C O Appiah, ${ }^{2}$ BSc; E X Amuzu, ${ }^{2}$ BSc; C A Frimpong, ${ }^{2}$ BSc; I Nyanor, ${ }^{2}$ MPH; \\ S B Nguah, ${ }^{4} \mathrm{MD} ; \mathrm{J}$ Sylverken, ${ }^{4} \mathrm{MD}$ \\ ${ }^{1}$ Department of Child Health, School of Medical Sciences, Kwame Nkrumah University of Science and Technology, Kumasi, Ghana \\ ${ }^{2}$ Research and Development Unit, Komfo Anokye Teaching Hospital, Kumasi, Ghana \\ ${ }^{3}$ Department of Internal Medicine, Komfo Anokye Teaching Hospital, Kumasi, Ghana \\ ${ }^{4}$ Department of Child Health, Komfo Anokye Teaching Hospital, Kumasi, Ghana
}

Corresponding author: D Ansong (ansongd@yahoo.com)

\begin{abstract}
Background. Childhood poisoning is an important cause of morbidity in both developed and developing countries. Epidemiological studies on accidental poisoning in children show a consistent pattern regarding age and gender. Childhood poisoning is predominant in children $<6$ years of age and has a male preponderance, as boys are more active with a drive to explore the environment.

Objective. To document the epidemiology of home poisonings in Kumasi and its environs.

Methods. We conducted a retrospective study from January 2007 to January 2012 at the Komfo Anokye Teaching Hospital, a tertiary hospital in Ghana.

Results. Poisoning is a significant health problem in the study area. A total of 253 children reported to the hospital with poisoning over the 61-month period, with an average of four cases per month. The male to female ratio was $1.58: 1$. The median age of the children was 24 months (interquartile range 24 - 48 months). Kerosene was the leading cause of poisoning (39.5\%).

Conclusion. Paediatric poisoning is a major health hazard in children living in Kumasi and its environs. This can possibly be attributed to a lack of adequate supervision of children and poor storage of harmful substances in homes. Multidisciplinary interventions are needed to reduce the occurrence of the condition in the population at risk.
\end{abstract}

S Afr J Child Health 2016;10(1):68-70. DOI:10.7196/SAJCH.2016.v10i1.1055

In 2004, an estimated 346000 people died worldwide from unintentional poisoning, according to the World Health Organization; $91 \%$ of the deaths occurred in low- and middle-income countries. ${ }^{[1]}$ Poisoning is defined as exposure of an individual to a substance that can cause symptoms and signs of organ dysfunction leading to injury or death. ${ }^{[2]}$ Ingestion of poisons and other household products has the potential to increase morbidity and mortality in children worldwide. ${ }^{[3,4]}$ The ingestion can be accidental or non-accidental in younger children, but in older children - especially in high-income countries - it is mostly intentional. ${ }^{[5]}$

As children explore their environment as part of their natural development, they are exposed to poisons without knowing that they may be harmful. Medicinal and non-medicinal substances have been identified as common agents causing poisoning in children as well as adolescents. ${ }^{[6]}$ Common medicinal substances ingested by children are analgesics, anti-inflammatory agents, psychotropic drugs such as antidepressants and benzodiazepines, and related agents. ${ }^{[7]}$ Non-medicinal chemicals such as organophosphates, pesticides, insecticides, organic solvents and household agents such as bleach and caustic soda are also common causes of poisoning among children. ${ }^{[8]}$ Several studies have reported on childhood poisoning in both developed and developing countries. ${ }^{[4,6,7]}$ A previously reported comparative analysis carried out from January to June 2009 and January to June 2010 in the current study hospital revealed an increase in chemical poisoning. A six-fold increase in the incidence of caustic soda poisoning occurred during the period. ${ }^{[9]}$

Our objective was to study the records of paediatric patients presenting with poisoning between January 2007 and January 2012, in order to describe the demographic characteristics and identify the types of childhood poisonings in this paediatric population.

\section{Methods \\ Setting}

A retrospective study was conducted at Komfo Anokye Teaching Hospital in Kumasi, Ghana. The hospital is a tertiary hospital situated in the second largest city, with a population base of about two million. The hospital has 1000 beds with an average occupancy rate of about $150 \%$. The Paediatric Emergency Unit runs a 24-hour service, and it serves as the major referral centre for all emergencies in children aged 3 months to 16 years.

\section{Design}

A retrospective study design was used to collect all reported cases of poisoning in the Paediatric Emergency Unit between January 2007 and January 2012 (61 months). This period was chosen based on the reliability and availability of medical records for the study.

The study defined poison as any medicinal or non-medicinal substance, including food and food products, which was ingested inappropriately. A systematic review of all medical records of home poisoning reported to the emergency unit was conducted. Data on age, gender and type of poisons were extracted from records. Data collected were entered on the Epi-Info 3.2.1 database system (Centers for Disease Control, USA) and exported into STATA 8.1 software (StataCorp LP, USA) for analysis. Basic summary statistics of age and gender were conducted, and bivariate analysis of type of poisoning and age was also conducted.

Permission to conduct the study was obtained from the Committee on Human Research Publications and Ethics (CHRPE) and the Research and Development Unit of Komfo Anokye Teaching Hospital.

\section{Results}

A total of 253 cases of home poisoning had reported in person to the emergency unit of the hospital. (The data gathered did not include telephone enquiries but only cases that had reported to the emergency 
department for treatment.) On average, about four cases of home poisoning were reported to the Paediatric Emergency Unit of the Komfo Anokye Teaching Hospital every month over the study period of 61 months (Fig. 1).

The median age of children affected by poisoning was 24 months (interquartile range 24 - 48 months). There were more males $(n=155,61.3 \%)$ than females $(n=98$, $38.7 \%$ ) reported with poisoning, giving a male to female ratio of 1.58: 1 (Table 1).

Over $60 \%$ of the affected children were $<3$ years old. Out of 253 children identified, 25 (9.9\%) suffered from sodium hypochlorite ingestion, $19(7.5 \%)$ patients had ingested caustic soda, $16(6.3 \%)$ had food poisoning, $11(4.4 \%)$ had iron poisoning, and $4(1.6 \%)$ had ingested rat poison. The most frequently recorded poison was kerosene (100 subjects, $39.5 \%$ ), followed by other chemical ingestion in 70 patients (27.7\%) (Table 2).

\section{Discussion}

The study found that home poisonings are a cause of morbidity in children living in Kumasi and its environs. The most common causes of poisoning found in the study were kerosene, sodium hypochlorite and caustic soda. In communities in Ghana these chemicals are readily available for domestic activities such as cooking, cleaning and local soap preparation. The chemicals are stored in plastic water bottles that resemble those used for drinking water. Storage of these substances serves as a potential source of danger if they are within easy reach of the children in their homes. Kerosene poisoning was noted to be the leading cause of poisoning in the study (39.5\%). This result is similar to that in other studies that showed kerosene to be the leading source of poisoning in children. ${ }^{[10,11]}$ The study also showed that children $<3$ years of age were more commonly involved in childhood poisoning (74.3\%). Studies by Abbas et al. ${ }^{[12]}$ showed similar findings, with children $<3$ years having the highest incidence of poisoning $(46.5 \%)$ in their study sample. This may be attributable to lack of adequate supervision for children in this age group, who like to explore their environment. From January to July 2007 there was a spike in the number of cases of poisoning reported at the Paediatric Emergency Unit of Komfo Anokye Teaching Hospital. This spike may be attributable to the prolonged period of low electrical power generation in the country, with a resultant increase in the use of petroleum products as alternatives for sources of light. ${ }^{[13]}$

There was no marked difference in terms of age for caustic soda ingestion. Caustic soda poisoning is associated with life-threatening complications such as corrosive oesophagitis and oesophageal stricture, and its proportion in this study (7.5\%) is worrying. The use of

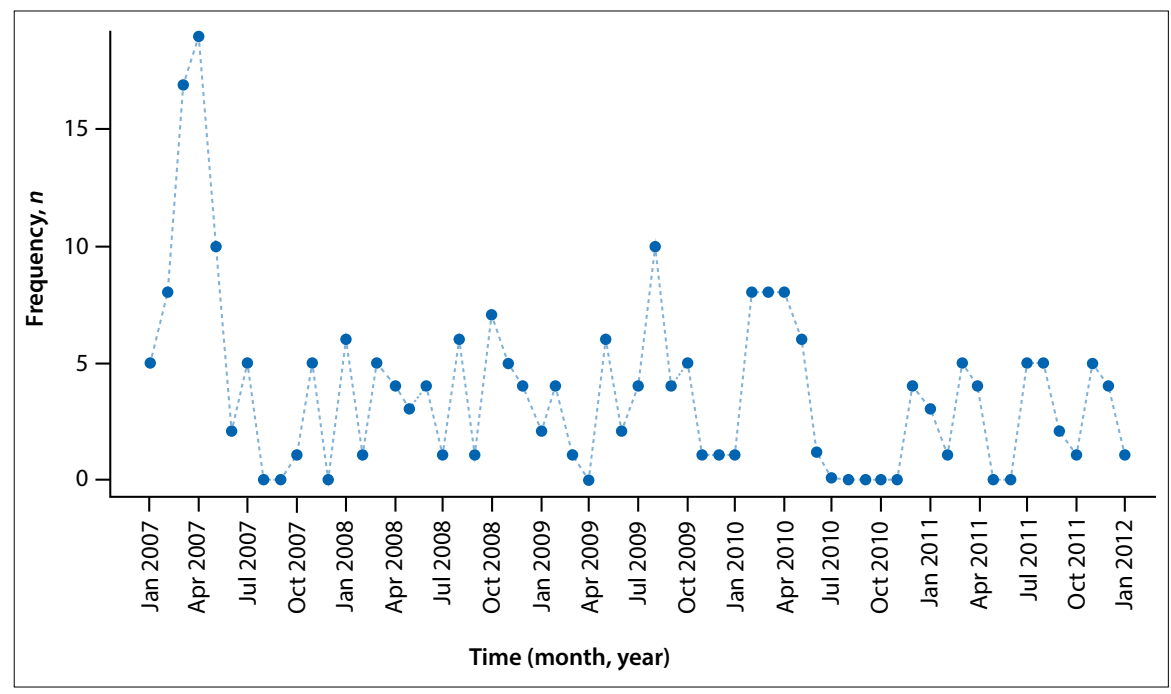

Fig. 1. Trend in accidental poisoning occurring in children reporting to a tertiary hospital in Ghana.

Table 1. Distribution of patients by sex and age groupings

\begin{tabular}{llll}
\hline \multirow{2}{*}{ Age in months } & \multicolumn{2}{c}{ Sex, $\boldsymbol{n}(\%)$} & \\
\cline { 2 - 3 } & Female & Male & Total, $\boldsymbol{n}(\%)$ \\
\hline$<12$ & $21(21.43)$ & $29(18.71)$ & $50(19.76)$ \\
$12-24$ & $26(26.53)$ & $62(40.00)$ & $88(34.78)$ \\
$25-36$ & $24(24.49)$ & $26(16.77)$ & $50(19.76)$ \\
$>36$ & $27(27.55)$ & $38(24.52)$ & $65(25.69)$ \\
Total & $98(100)$ & $155(100)$ & $253(100)$ \\
Median & & & 24
\end{tabular}

Table 2. Source of poisoning by age groupings

\begin{tabular}{llllll}
\hline & \multicolumn{4}{c}{ Age category (months), $\boldsymbol{n}$ (\%) } & \\
\cline { 2 - 5 } Diagnosis & $<\mathbf{1 2}$ & $\mathbf{1 2 - 2 4}$ & $\mathbf{2 5 - 3 6}$ & $>\mathbf{3 6}$ & Total, $\boldsymbol{n}$ (\%) \\
\hline Caustic soda ingestion & $4(21.5)$ & $5(26.3)$ & $5(26.3)$ & $5(26.3)$ & $19(7.5)$ \\
Drug ingestion & $1(12.5)$ & $1(12.5)$ & $4(50.0)$ & $2(25.0)$ & $8(3.2)$ \\
Food poisoning & $2(12.5)$ & $2(12.5)$ & $1(6.3)$ & $11(68.8)$ & $16(6.3)$ \\
Iron poisoning & $5(45.5)$ & $3(27.3)$ & $1(9.1)$ & $2(18.2)$ & $11(4.4)$ \\
Kerosene ingestion & $15(15.0)$ & $40(40.0)$ & $20(20.0)$ & $25(25.0)$ & $100(39.5)$ \\
Sodium hypochlorite & $7(28.0)$ & $11(44.0)$ & $2(8.0)$ & $5(20.0)$ & $25(9.9)$ \\
(parazone) ingestion & & & & & \\
Rat poisoning & $1(25.0)$ & $1(25.0)$ & $0(0.0)$ & $2(50.0)$ & $4(1.6)$ \\
Other chemical ingestions & $15(21.4)$ & $25(35.7)$ & $17(24.3)$ & $13(18.6)$ & $70(27.7)$ \\
Total & $50(19.8)$ & $88(34.8)$ & $50(19.8)$ & $65(25.7)$ & $253(100)$
\end{tabular}

${ }^{*}$ Other chemical ingestions refer to any other poisons including weedicides, pesticides, etc. that appeared only once in the data.

this agent in households for making local soap and the poor methods of storage are contributing to the availability of this poison to children. Detailed studies need to be done on poisoning in children of Ghanaian homes to influence public health policies and interventions.

Food poisoning was noted to have a high incidence in children $>36$ months $(68.8 \%)$.
This is an expected finding as children in this age group are starting to eat independently and have more freedom to explore the variety of food options with less supervision. Iron poisoning had a significant representation (4.4\%). This may be attributable to the attractive packaging and poor storage of iron-containing tablets, making them readily available and appealing to children. 
Other drugs and rat poisoning had $3.2 \%$ and $1.6 \%$ representation, respectively. This is a large proportion and may be due to poor storage and poor compliance with safety measures in homes. The recent liberalisation of policies governing the sale of agrochemicals and animal poisons in Ghana may have contributed to this problem. The liberalisation has also raised safety concerns regarding the storage and use of these poisons within homes.

This retrospective study provided limited data but more details will emerge from our current longitudinal study aimed at monitoring all children reporting to the study hospital with poisoning. The additional information will support the evidence from the retrospective study and highlight the need to provide a comprehensive public health approach to this health problem.

\section{Conclusion}

Childhood poisoning is a major public health problem in developing country such as Ghana. Data gathered from research aimed at understanding the underlying causes may be used to formulate public health policies including comprehensive health education of the public. Children will continue to be exposed to poisonings until the lack of education of the caregivers is addressed.

\section{References}

1. World Health Organization. Poisoning Prevention and Management. http:// www.who.int/ipcs/poisons/en/ (accessed 5 January 2013).
2. Osterhoudt K, Shannon M, Henretig F. Toxicological emergences. In: Fleisher G, Ludwig S, eds. Textbook of Pediatric Emergency Medicine. 4th ed. Philadelphia: Lippincott William \& Wilkins, 2000:887-897.

3. Walton WW. An evaluation of the Poison Prevention Packaging Act. Pediatrics 1982;69(3):363-370.

4. Lawson GR, Craft AW, Jackson RH. Changing pattern of poisoning in children in Newcastle, 1974 - 1981. Br Med J Clin Res Ed 1983;287(6384):15-17.

5. Sibert J, Davies P. Poisoning, accidents and sudden infant death syndrome. In: Campbell A, McIntosh M, eds. Forfar and Arneil's Textbook of Paediatrics. 4th ed. London: Churchill Livingstone, 1992:1777-1800.

6. Aslam M, Boluch GR, Wagar H, Akbar M, Aniga H. Accidental poisoning in children. Pak Paediatr J 2002;26(2):67-72.

7. James LP, James L, Abel K, Wilkinson J, Simpson PM, Nichols MH Phenothiazine, butyrophenone, and other psychotropic medication poisonings in children and adolescents. Clin Toxicol 2000;38(6):615-623. [http://dx.doi. org/10.1081/clt-100102010]

8. Lam L. Childhood and adolescence poisoning in NSW, Australia: An analysis of age, sex, geographic, and poison types. Inj Prev 2003;9(4):338-342. [http:// dx.doi.org/10.1136/ip.9.4.338]

9. Weldon E, Martey PM. Caustic soda poisoning in Ghana - an alarming increase. Paediatr Int Child Health 2012;32(3):158-160. [http://dx.doi.org/10. 1179/2046905512y.0000000007]

10. Balme K, Roberts JC, Glasstone M, Curling L, Mann MD. The changing trends of childhood poisoning at a tertiary children's hospital in South Africa. S Afr Med J 2012;102(3):142-146.

11. Brata Ghosh V, Jhamb U, Singhal R, Krishnan R. Common childhood poisonings and their outcome in a tertiary care center in Delhi. Indian J Pediatr 2013;80(6):516-518. [http://dx.doi.org/10.1007/s12098-012-0879-5]

12. Abbas SK, Tikmani SS, Siddiqui NT. Accidental poisoning in children. J Pak Med Assoc 2012;62(4):331-334.

13. Boateng MOA. New load shedding programme out. http://edition.myjoyonline. com/pages/news/200703/2836.php (accessed 12 February 2016). 